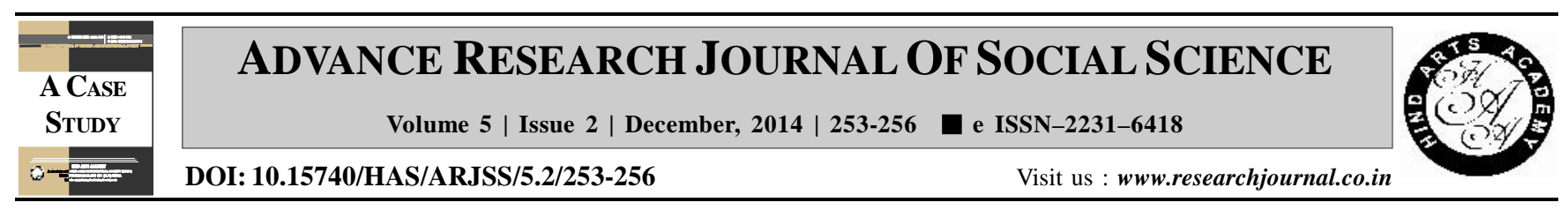

\title{
Child worker and their education
}

Hare Krishna Mandal

Department of Economics, Government College of Education, BANIPUR (W.B.) INDIA

\section{ARTICLE INFO :}

$\begin{array}{lll}\text { Received } & : & 30.10 .2014 \\ \text { Accepted } & : & 27.11 .2014\end{array}$

KEY WORDS :

Child worker,

Child education
HOW TO CITE THIS ARTICLE :

Mandal, Hare Krishna (2014). Child worker and their education, Adv. Res. J. Soc. Sci., 5 (2) : 253256.

\begin{abstract}
Education can become a powerful tool to train individuals and channelies their thought process in right direction with superb power of positive thinking. The Constitution (Article 21A) made it obligatory for the government to provide free and compulsory education to all children till the age of 14 years. Article 45 also refers to the provision for free and compulsory education for children. The RTE ACT-2009 has made a historic moment for the children of India .But miles to go to make the UEE a reality. The target year of SSA to reach the goal is 2015 which would hardly be achieved. Still today one in five children leaves school before reaching grade 5 and almost one-third before reaching grade 8. The ILO has recently estimated that some 217.7 million children ages 5 to 17 are engaged in child labour around the world. Of these, some 126.3 million are caught in the worst forms of child labour. In India if you take the children up to 14, according to Census-2010, the total number of children in the workforce is 1,26,26505-almost the same as previous census of 2001. In spite of utmost efforts why we have failed to reach the disadvantaged section of the society with the formal primary education system? What are the main causes behind the severe problems of illiteracy together with the problem of child labour? Is there any way-out to solve the problem of illiteracy among the child labour? If the parents of the out of school children are convinced in such a manner that they can consider expenditure, even on primary education, in terms of time and money, as one kind of investment, then their attitude towards education may be changed to the positive direction. In such a situation they may send their wards for primary education instead of sending them for work. separate arrangements for making them literate may be attempted for the child labour beyond their normal work time .This may be termed as Need Based Non-Formal Education. It is the combination of preliminary education and simple training side by side.
\end{abstract}

